\title{
Estresse oxidativo: conceito, implicações e fatores modulatórios
}

\author{
Oxidative stress: concept, implications \\ and modulating factors \\ and modulating factors
}

\author{
Kiriaque Barra Ferreira BARBOSA ${ }^{1}$ \\ Neuza Maria Brunoro COSTA ${ }^{2}$ \\ Rita de Cássia Gonçalves ALFENAS² \\ Sérgio Oliveira DE PAULA ${ }^{3}$ \\ Valéria Paula Rodrigues $\mathrm{MINIM}^{4}$ \\ Josefina BRESSAN ${ }^{1}$
}

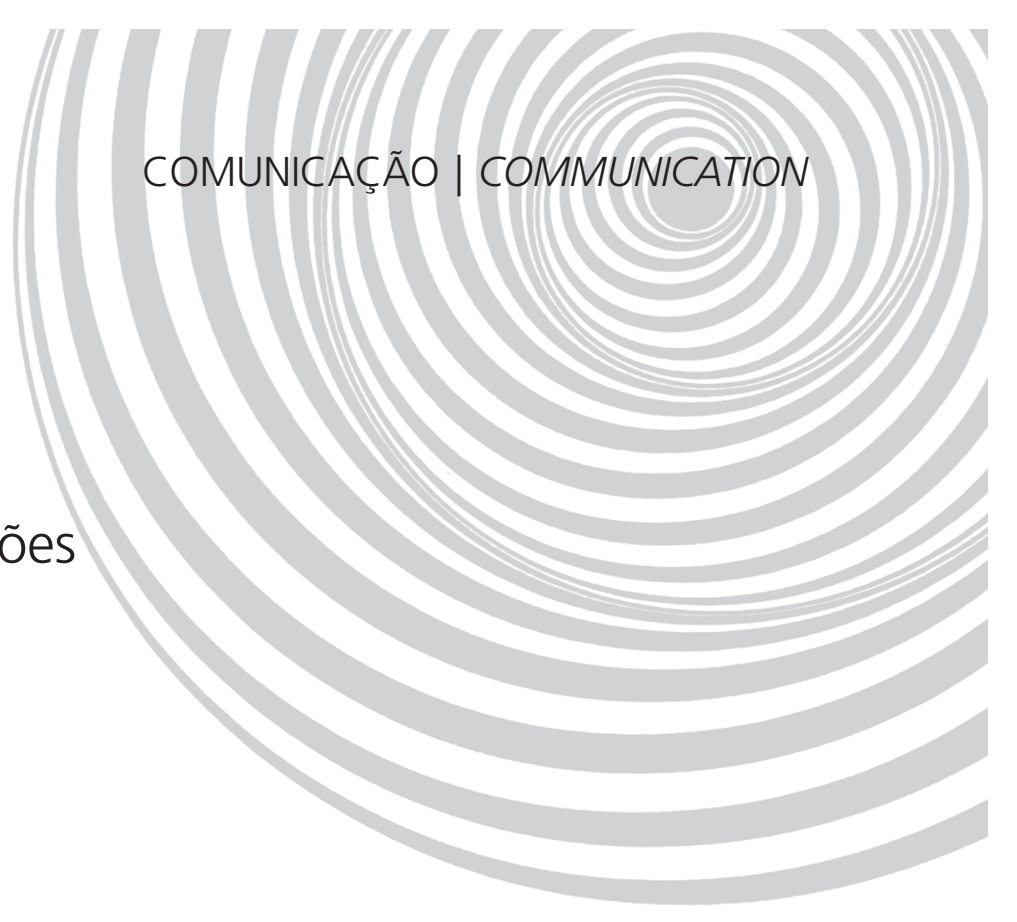

R E S U M O

O estresse oxidativo decorre de um desequilíbrio entre a geração de compostos oxidantes e a atuação dos sistemas de defesa antioxidante. A geração de radicais livres e/ou espécies reativas não radicais é resultante do metabolismo de oxigênio. A mitocôndria, por meio da cadeia transportadora de elétrons, é a principal fonte geradora. O sistema de defesa antioxidante tem a função de inibir e/ou reduzir os danos causados pela ação deletéria dos radicais livres e/ou espécies reativas não radicais. Esse sistema, usualmente, é dividido em enzimático (superóxido dismutase, catalase e glutationa peroxidase) e não-enzimático. No último caso, é constituído por grande variedade de substâncias antioxidantes, que podem ter origem endógena ou dietética. Objetivou-se revisar os principais mecanismos de geração de radicais livres, bem como a ação dos agentes mais relevantes do sistema de defesa antioxidante, ressaltando suas implicações sobre os marcadores do estresse oxidativo. Também serão abordados os principais fatores exógenos moduladores do estresse oxidativo.

Termos de indexação: Antioxidantes. Espécies reativas de nitrogênio. Espécies reativas de oxigênio. Estresse oxidativo. Radicais livres.

A B S T R A C T

There is evidence that oxidative stress, defined as a persistent imbalance between the production of highly oxidative compounds and antioxidant defenses, leads to tissue damage. Oxygen metabolism generates free

\footnotetext{
1 Universidade Federal de Viçosa, Departamento de Tecnologia de Alimentos, Programa de Pós-Graduação em Ciência e Tecnologia de Alimentos. Av. P.H. Rolfs, s/n., Campus Universitário, 36570-000, Viçosa, MG, Brasil. Correspondência para/Correspondence to: J. BRESSAN. E-mail: <jbrm@ufv.br>.

2 Universidade Federal de Viçosa, Departamento de Nutrição e Saúde. Viçosa, MG, Brasil.

3 Universidade Federal de Viçosa, Departamento de Biologia Geral. Viçosa, MG, Brasil.

${ }^{4}$ Universidade Federal de Viçosa, Departamento de Tecnologia de Alimentos. Viçosa, MG, Brasil.
} 
630 | K.B.F. BARBOSA et al.

radicals and/or non-radical reactive oxygen species. The mitochondria, through the electron transport chain, are the main generator of these species. The antioxidant defense system has the function of inhibiting and/or reducing the damage caused by the deleterious free radicals and/or non-radical reactive oxygen species. This system is divided into enzymatic (superoxide dismutase, catalase and g/utathione peroxidase), and nonenzymatic. The nonenzymatic system consists of a variety of antioxidant substances, which may be endogenous or dietary. This study proposed to review the main mechanisms of reactive oxygen species generation and the role of the most relevant agents of the antioxidant defense system on the biomarkers of oxidative stress. The main exogenous factors that modulate oxidative stress will also be discussed.

Indexing terms: Oxidative stress. Free radicals. Reactive oxygen species. Antioxidants. Reactive nitrogen species.

\section{N T R O D U ÇÃ O}

A geração de radicais livres constitui, por excelência, um processo contínuo e fisiológico, cumprindo funções biológicas relevantes. Durante os processos metabólicos, esses radicais atuam como mediadores para a transferência de elétrons nas várias reações bioquímicas. Sua produção, em proporções adequadas, possibilita a geração de ATP (energia), por meio da cadeia transportadora de elétrons; fertilização do óvulo; ativação de genes; e participação de mecanismos de defesa durante o processo de infecção. Porém, a produção excessiva pode conduzir a danos oxidativos ${ }^{1,2}$.

A produção contínua de radicais livres durante os processos metabólicos culminou no desenvolvimento de mecanismos de defesa antioxidante. Estes têm o objetivo de limitar os níveis intracelulares de tais espécies reativas e controlar a ocorrência de danos decorrentes ${ }^{1,3}$.

A instalação do processo de estresse oxidativo decorre da existência de um desequilíbrio entre compostos oxidantes e antioxidantes, em favor da geração excessiva de radicais livres ou em detrimento da velocidade de remoção desses. Tal processo conduz à oxidação de biomoléculas com consequente perda de suas funções biológicas e/ou desequilíbrio homeostático, cuja manifestação é o dano oxidativo potencial contra células e tecidos ${ }^{4}$. A cronicidade do processo em questão tem relevantes implicações sobre o processo etiológico de numerosas enfermidades crônicas não transmissíveis, entre elas a aterosclerose, diabetes, obesidade, transtornos neurodegenerativos e câncer ${ }^{5}$. Ferrari ${ }^{6}$, em estudo de revisão, ratifica que a geração de radicais livres desencadeia eventos patológicos que, por sua vez, estão envolvidos nos processos cardiovasculares, carcinogênicos e neurodegenerativos.

Diante do exposto, objetivou-se nesse estudo revisar os principais mecanismos de geração de radicais livres, bem como a ação dos agentes mais relevantes do sistema de defesa antioxidante, ressaltando suas implicações sobre os marcadores do estresse oxidativo. Também serão abordados os principais fatores exógenos intervenientes no processo de instalação do estresse oxidativo.

Essa revisão de literatura foi realizada utilizando-se os termos "estresse oxidativo", "radicais livres", "espécies reativas", "antioxidantes", "dano oxidativo" e "biomarcadores", bem como seus correspondentes em inglês. A variedade dos termos utilizados permitiu uma abrangência significativa, com o intuito de realizar uma ampla busca sobre o tema. Procedeu-se à consulta por meio das bases de dados PubMed, HighWire e SciELO, abrangendo os anos de 2000 a 2009, incluindo também os artigos relevantes ao tema, publicados anteriormente, citados nos artigos previamente selecionados. Foram incluídos, sobretudo, estudos de intervenção, randomizados e controlados, além de estudos com animais de experimentação. Os estudos com desenhos metodológicos distintos foram utilizados, predominantemente, para a elaboração de conceitos, bem como para a descrição de mecanismos de ação.

\section{MECANISMOS DE GERAÇÃO DERADICAIS LIVRES}

Os mecanismos de geração de radicais livres ocorrem, normalmente, nas mitocôndrias, membranas celulares e no citoplasma. Tais meca- 
nismos podem, especialmente, ser favorecidos pelos íons ferro e cobre ${ }^{7}$. A mitocôndria, por meio da cadeia transportadora de elétrons, é a principal fonte geradora de radicais livres ${ }^{5}$.

Em condições fisiológicas, os organismos aeróbicos metabolizam $85 \%$ a $90 \%$ do oxigênio $\left(\mathrm{O}_{2}\right)$ consumido na mitocôndria, por meio da cadeia transportadora de elétrons. Os restantes 10\% a $15 \%$ são utilizados por diversas enzimas oxidases e oxigenases e, ainda, por reações químicas de oxidação direta ${ }^{8}$.

Na mitocôndria, o $\mathrm{O}_{2}$ sofre redução tetravalente, com aceitação de quatro elétrons, resultando na formação de água (Figura 1). A enzima catalisadora dessa reação é a citocromo oxidase. Na parte terminal da cadeia transportadora de elétrons, a referida enzima oxida quatro moléculas de citocromo c removendo um elétron de cada uma delas. Esses elétrons são adicionados ao $\mathrm{O}_{2}$ para formar água. A ação da citocromo oxidase controla a geração de radicais livres, impedindo sua geração excessiva na mitocôndria. No entanto, cerca de $2 \%$ a $5 \%$ do oxigênio metabolizado nas mitocôndrias são desviados para outra via metabólica, e reduzidos de forma univalente, dando origem aos radicais livres ${ }^{2,7,8}$.

Em face da redução univalente do $\mathrm{O}_{2}$ são gerados os radicais superóxido $\left(\mathrm{O}_{2}{ }^{*}\right)$, hidroxila $\left(\mathrm{OH}^{\circ}\right)$ e, ainda, peróxido de hidrogênio $\left(\mathrm{H}_{2} \mathrm{O}_{2}\right)$. Esse processo se dá mediante reações específicas, catalisadas por enzimas e com a participação dos íons ferro e de cobre (Figura 1). $\mathrm{O}_{2} \mathrm{O}_{2}$, apesar de não ser um radical livre, por não ter um elétron desemparelhado na sua última camada eletrônica, é uma espécie com alto potencial reativo. Por participar da reação de geração de $\mathrm{OH}$ • tem ação deletéria potencial, uma vez que esse se constitui no mais reativo dos radicais livres, pois pode alterar qualquer estrutura celular que se encontre próxima. Diferente dos radicais livres, $\mathrm{O}_{2} \mathrm{O}_{2}$ tem vida longa e é capaz de atravessar as membranas celulares apresentando-se potencialmente tóxico para as células. Esta toxicidade pode ser aumentada em dez mil vezes pela presença de ferro ${ }^{2,8}$.

Além da capacidade do $\mathrm{O}_{2}{ }^{\bullet}$ em participar de reações de geração de $\mathrm{OH}^{\bullet}$, pode ainda, por meio da reação com o radical livre óxido nítrico $\left(\mathrm{NO}{ }^{*}\right)$, gerar a espécie reativa de nitrogênio, peroxinitrito (ONOO), também potencialmente reati$\mathrm{va}^{5,8}$ (Figura 1).

Os íons ferro e cobre são muito ativos em reações de óxido-redução, o que os capacitam como potentes catalisadores das reações de geração de radicais livres. A participação desses metais se dá, especialmente, por meio das reações de Fenton e Haber-Weiss. A primeira diz respeito à geração de radical $\mathrm{OH}^{*}$, por meio da reação do $\mathrm{H}_{2} \mathrm{O}_{2}$ com os íons em questão, ao passo que, na segunda, estes íons catalisam a reação entre o $\mathrm{H}_{2} \mathrm{O}_{2}$ e o radical $\mathrm{O}_{2}{ }^{\circ}$, a fim de gerar, da mesma forma, o radical $\mathrm{OH}^{\bullet \cdot, 8}$ (Figura 1).

A ligação do ferro e cobre às proteínas específicas: transferrina, ferritina e ceruloplasmina, por meio da quais estes são transportados, utilizados e estocados, previne e/ou minimiza as reações de geração de radicais livres catalisadas por esses metais. No citoplasma de células hepáticas, o ferro livre (não ligado à ferritina) é facilmente dissociado na forma de íon, o que o torna cataliticamente ativo e apto para participar de reações de óxido-redução e, consequentemente, de geração de radicais livres 7,9 .

Os ácidos graxos poli-insaturados contidos nas membranas celulares fazem com que essas sejam potentes geradoras de radicais livres, alcoxila $\left(\mathrm{LO}^{*}\right)$ e peroxila $\left(\mathrm{LO}_{2}{ }^{\circ}\right.$ ), por meio da lipoperoxidação. Tal processo constitui-se de reações em cadeia, representadas pelas etapas de iniciação, propagação e terminação².

$\mathrm{O}$ radical $\mathrm{OH}^{\bullet}$, por meio da retirada de um átomo de hidrogênio dos ácidos graxos poli-insaturados da membrana celular, desempenha importante papel na lipoperoxidação, sendo considerado o principal iniciador de tal processo ${ }^{9}$. Entretanto, a participação do ferro também é considerada fator determinante, ressaltando-se a importância da relação equimolar entre $\mathrm{Fe}^{3+} / \mathrm{Fe}^{2+}$, para possibilitar a iniciação desse processo. Os íons ferro agem como catalisadores da conversão de hidroperóxidos lipídicos ( $\mathrm{LOOH}$ ) em radicais $\mathrm{LO}^{\bullet} \mathrm{e}$ $\mathrm{LO}_{2}{ }^{\circ}$, que, por serem potencialmente reativos, iniciam uma nova cadeia de reações, as quais po- 
dem ser rápidas ou lentas, de acordo com a valência do ferro².

Outra importante fonte geradora de radicais livres são as enzimas NADPH oxidases (Nicotinamide Adenine Dinucleotide Phosphate Oxidases). Essas se referem a proteínas transmembrana que têm, por excelência, a função de transferir os elétrons através das membranas celulares. Geralmente, o aceptor de elétrons é o oxigênio e, dessa forma, em decorrência desse processo, gera-se o radical $\mathrm{O}_{2}$. Tais enzimas existem em pelo menos seis isoformas, diferindo quanto ao local de expressão e co-fatores necessários para a sua ativação ${ }^{10}$.

\section{Sistema de defesa antioxidante}

O sistema de defesa antioxidante tem a função de inibir e/ou reduzir os danos causados pela ação deletéria dos radicais livres ou das espécies reativas não-radicais. Tais ações podem ser alcançadas por meio de diferentes mecanismos de ação: impedindo a formação dos radicais livres ou espécies não-radicais (sistemas de prevenção), impedindo a ação desses (sistemas varredores) ou, ainda, favorecendo o reparo e a reconstituição das estruturas biológicas lesadas (sistemas de reparo) $)^{711}$.

Usualmente, esse sistema é dividido em enzimático e não-enzimático. No último caso, é constituído por grande variedade de substâncias antioxidantes, que podem ter origem endógena ou dietética (Tabela 1). Os antioxidantes são definidos como qualquer substância que, presente em menores concentrações que as do substrato oxidável, seja capaz de atrasar ou inibir a oxidação deste de maneira eficaz. Tais substâncias podem agir diretamente, neutralizando a ação dos radi-

Tabela 1. Ações e mecanismos de diversas substâncias antioxidantes.

\begin{tabular}{|c|c|c|}
\hline Antioxidantes & Ação & Referências \\
\hline \multicolumn{3}{|l|}{ Não enzimáticos (de origem dietética) } \\
\hline Vitamina $A$ ( $\beta$-caroteno) & Proteção contra a oxidação de lipídeos e DNA & Rodrigo et al. ${ }^{12}$ \\
\hline Vitamina C (ácido ascórbico) & $\begin{array}{l}\text { Inibição das EROs (agente reductor). Estimula o poder antioxidante } \\
\text { da vitamina E e selênio. Proteção contra danos causados pela } \\
\text { LDL-ox }\end{array}$ & Rodrigo et al. ${ }^{12}$ \\
\hline Vitamina $E$ ( $\alpha$-tocoferol) & $\begin{array}{l}\text { Protección contra la peroxidación de los ácidos grasos insaturados } \\
\text { de la membrana celular y de las LDL. Converte } \mathrm{O}_{2} \cdot \text { e }_{2} \mathrm{O}_{2} \text { em for- } \\
\text { mas menos reactivas }\end{array}$ & Rodrigo et al. ${ }^{12}$ \\
\hline $\mathrm{Cu}, \mathrm{Zn}, \mathrm{Mn}, \mathrm{Se}$ & $\begin{array}{l}\text { Cofatores das enzimas antioxidantes SOD-Cu/Zn, SOD-Mn e } \\
\text { GSH-Pox }\end{array}$ & Vincent et al. ${ }^{13}$ \\
\hline $\begin{array}{l}\text { Otros carotenóides (licopeno) } \\
\text { (Autor, é otros em español ou outros em por- } \\
\text { tuguês?) }\end{array}$ & $\begin{array}{l}\text { Proteção contra a oxidação de lipídeos, LDL, proteínas e DNA. Se- } \\
\text { questra e inativa os radicais livres }\end{array}$ & Visioli et al. ${ }^{14}$ \\
\hline $\begin{array}{l}\text { Fitoquímicos (resveratrol, catequinas, querce- } \\
\text { tinas, ácidos fenólicos e outros) }\end{array}$ & Proteção contra a oxidação de lipídeos e DNA & Fito et al. ${ }^{15}$ \\
\hline \multicolumn{3}{|l|}{ Enzimáticos } \\
\hline SOD & $\begin{array}{l}\text { SOD-Cu/Zn (citoplasma), SOD-Mn (mitocôndria). Catalisa a con- } \\
\text { versão do radical superóxido }\left(\mathrm{O}_{2} \cdot\right) \text { em peróxido de hidrogênio }\left(\mathrm{H}_{2} \mathrm{O}_{2}\right)\end{array}$ & Vincent et al. ${ }^{13}$ \\
\hline CAT & Catalisa a conversão de $\mathrm{H}_{2} \mathrm{O}_{2}$ em $\mathrm{O}_{2}$ e $\mathrm{H}_{2} \mathrm{O}$ & Vincent et al. ${ }^{13}$ \\
\hline GPx & Catalisa a redução do $\mathrm{H}_{2} \mathrm{O}_{2}$ a $\mathrm{H}_{2} \mathrm{O}$ & Vincent et al. ${ }^{13}$ \\
\hline
\end{tabular}


cais livres e espécies não-radicais, ou indiretamente, participando dos sistemas enzimáticos com tal capacidade ${ }^{4}$.

\section{Sistema enzimático}

O sistema de defesa enzimático inclui as enzimas Superóxido Dismutase (SOD), Catalase (CAT) e Glutationa Peroxidase (GPx) (Tabela 1). Essas enzimas agem por meio de mecanismos de prevenção, impedindo e/ou controlando a formação de radicais livres e espécies não-radicais, envolvidos com a iniciação das reações em cadeia que culminam com propagação e amplificação do processo e, consequentemente, com a ocorrência de danos oxidativos ${ }^{2,8}$.

As enzimas CAT e GPx agem com o mesmo propósito, ou seja, o de impedir o acúmulo de peróxido de hidrogênio. Tal ação integrada é de grande importância, uma vez que essa espécie reativa, por meio das reações de Fenton e Haber-Weiss, mediante a participação dos metais ferro e cobre, culmina na geração do radical $\mathrm{OH}^{*}$ (Figura 1), contra o qual não há sistema enzimático de defesa ${ }^{2,8}$.

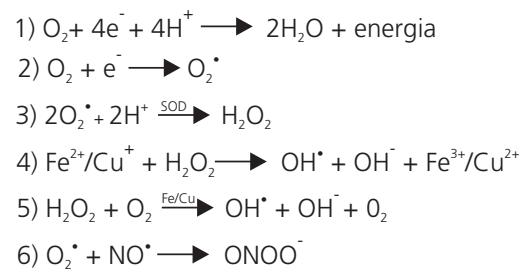

Figura 1. Formação mitocondrial de radicais livres via cadeia transportadora de elétrons.

Nota: 1) Redução tetravalente do oxigênio, por meio da qual recebe quatro elétrons (e) e quatro íons de hidrogênio $\left(\mathrm{H}^{+}\right)$, formando duas moléculas de água $\left(\mathrm{H}_{2} \mathrm{O}\right)$ e liberando energia. 2) Geração do radical superóxido $\left(\mathrm{O}_{2}{ }^{*}\right)$ pela adição de um elétron a uma molécula de oxigênio no estado fundamental $\left(\mathrm{O}_{2}\right)$. 3) Por meio de um processo denominado dismutação, o radical $\mathrm{O}_{2}{ }^{\circ}$, ao receber íons de hidrogênio, gera peróxido de hidrogênio $\left(\mathrm{H}_{2} \mathrm{O}_{2}\right)$. Tal reação é catalisada pela superóxido dismutase (SOD), que acelera a reação na ordem de $10^{4}$ vezes. 4) Reação de Fenton: quando o $\mathrm{H}_{2} \mathrm{O}_{2}$ reage com íons ferro $\left(\mathrm{Fe}^{2+}\right)$ ou cobre $\left(\mathrm{Cu}^{+}\right)$é gerado o radical hidroxila $\left(\mathrm{OH}^{*}\right)$. 5) Reação de Haber-Weiss: os referidos íns também podem catalisar a reação entre $\mathrm{H}_{2} \mathrm{O}_{2}$ e $\mathrm{O}_{2} \cdot$ gerando, da mesma forma, $\mathrm{OH}^{*}$. 6) O radical $\mathrm{O}_{2}$. pode também reagir com o óxido nítrico (NO*) gerando peroxinitrito $(\mathrm{ONOO})^{8}$.
O referido radical $\left(\mathrm{OH}^{\circ}\right)$ vem sendo indicado como o de maior potencial reativo e com extrema instabilidade (vida média de $10^{-9}$ segundos). Essas características os capacitam como o radical livre mais propício na produção de danos oxidativos. Além de ser o principal iniciador do processo de peroxidação lipídica, tendo como consequência a alteração da função biológica das membranas celulares, esse radical é capaz de agir sobre as proteínas, alterando-as em relação à sua estrutura e/ou função biológica. Seu ataque ao DNA possibilita a ocorrência de mutações ${ }^{9}$.

Considerando a potencialidade do radical $\mathrm{OH}^{\bullet}$ e o fato da não existência de defesa enzimática especializada, é de extrema importância a manutenção do perfeito equilíbrio entre as enzimas antioxidantes, com o propósito de promover a manutenção da integralidade celular. Assim, a GPx merece atenção especial, uma vez que sua ação depende da manutenção do ciclo redox da glutationa, por meio do controle da relação entre glutationa reduzida (GSH) e oxidada (GSSG) 2,8,17 (Figura 2).

A atividade das enzimas em questão muitas vezes depende da participação de cofatores enzimáticos, especialmente antioxidantes de origem dietética. Tais co-fatores podem diferir de acordo com os compartimentos celulares de ação das enzimas. A SOD pode ser encontrada sob duas formas: no citoplasma, é dependente de cobre e zinco (SOD-Cu/Zn), enquanto na mitocôndria, necessita do manganês como co-fator (SOD-Mn). A GPx também existe sob duas formas: dependente e independente de selênio e pode apresentar-se no citoplasma ou na mitocôndria ${ }^{2,5}$.

\section{Sistema não-enzimático}

O sistema de defesa não-enzimático inclui, especialmente, os compostos antioxidantes de origem dietética, entre os quais se destacam: vitaminas, minerais e compostos fenólicos. O ácido ascórbico (vitamina $C$ ), o $\alpha$-tocoferol e $\beta$-caroteno, precursores das vitaminas $\mathrm{E}$ e $\mathrm{A}$, respectivamente, são compostos vitamínicos potencialmente antioxidantes. Outros carotenóides sem atividade de 
vitamina A, como licopeno, luteína e zeaxan-tina, também o são. Entre os minerais destacam--se o zinco, cobre, selênio e magnésio 3,18 (Tabela 1).

Usualmente, os estudos que se referem à ação de compostos antioxidantes limitam-nos à avaliação de nutrientes e/ou alimentos isola$\operatorname{dos}^{19-28}$, em detrimento da consideração dos padrões dietéticos. Tal fato consiste em relevante limitação metodológica, uma vez que não se considera a interação entre os vários nutrientes e alimentos que podem atuar em sinergia na proteção contra os danos oxidativos às células e aos tecidos. Assim, pode-se incorrer em erros na interpretação dos resultados referentes ao potencial antioxidante dos compostos estudados.

A vitamina C é, por excelência, um antioxidante em potencial. No entanto, a presença de metais de transição como o ferro possibilita sua

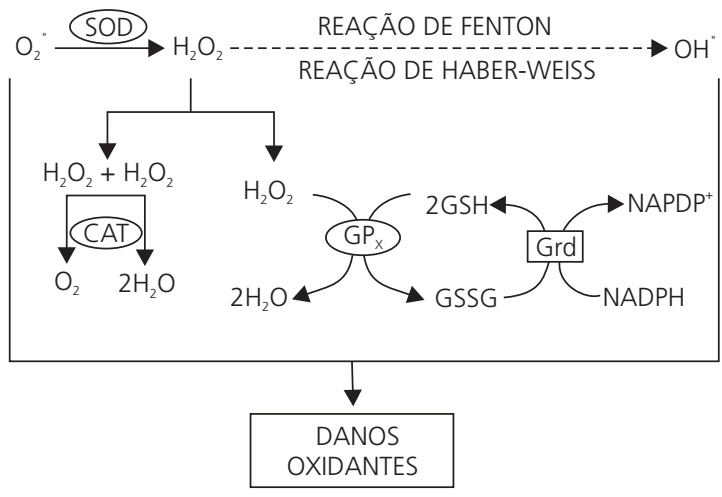

Figura 2. Integração dos sistemas de defesa enzimático.

Nota: Por meio da reação de dismutação, a superóxido dismutase (SOD) catalisa a geração de peróxido de hidrogênio $\left(\mathrm{H}_{2} \mathrm{O}_{2}\right)$ a partir do radical superóxido $\left(\mathrm{O}_{2}{ }^{\circ}\right)$. As enzimas catalase (CAT) e glutationa peroxidase (GPx) se integram para impedir o acúmulo de $\mathrm{H}_{2} \mathrm{O}_{2}$ que, apesar de não ser um radical livre, é igualmente reativo e capaz de promover danos potenciais. O acúmulo dessa espécie reativa $\left(\mathrm{H}_{2} \mathrm{O}_{2}\right)$ possibilita, por meio das reações de Fenton e HaberWeiss, a geração do radical hidroxila $\left(\mathrm{OH}^{\bullet}\right)$, contra o qual não existe defesa enzimática. $\mathrm{A} \mathrm{GPx}$ reduz $\mathrm{o}_{2} \mathrm{O}_{2}$ à água, no entanto o faz à custa da conversão da glutationa reduzida (GSH) em oxidada (GSSG), essa última que promove ação oxidante em função da ligação dissulfeto existente em sua estrutura. Assim, é de extrema importância a ação da glutationa redutase (GRd), responsável pela recuperação da glutationa reduzida (GSH), possibilitando a manutenção da integralidade do ciclo redox da glutationa e, consequentemente, do equilíbrio adequado entre os sistemas de defesa enzimáticos ${ }^{17}$. ação oxidante, tornando-a capaz de produzir espécies radicais $\left(\mathrm{OH}^{\bullet}\right)$ e não-radicais $\left(\mathrm{H}_{2} \mathrm{O}_{2}\right)^{3}$.

Estudo realizado com cultura de células mostrou que essas, quando incubadas em $\mathrm{H}_{2} \mathrm{O}_{2}$, sofreram danos em resposta à ação oxidativa dessa espécie. A vitamina C, em presença de ferro, aumentou a expressão dos danos referidos. Os autores sugerem o envolvimento da vitamina $C$ na regulação do metabolismo de ferro, aumentando sua absorção e tornando-o mais apto a desempenhar sua ação catalítica sobre as reações de Fenton, resultando na conversão do $\mathrm{H}_{2} \mathrm{O}_{2}$ em radicais $\mathrm{OH}^{*}$, potencialmente mais reativos. Também ressaltaram que, concomitantemente, ocorre a modulação da expressão de dois genes relacionados aos receptores de transferrina e ferritina ${ }^{29}$.

Outra interação diz respeito ao composto quercetina, flavonóide amplamente encontrado no vinho tinto. Tal composto é potencialmente antioxidante. Entretanto, pode reagir com ferro e tornar-se um pró-oxidante ${ }^{3}$.

As vitaminas $C$ e $E$, por sua vez, demonstram interação cooperativa na inibição da peroxidação lipídica e na proteção contra danos oxidativos ao DNA ${ }^{3}$. No entanto, Huang et al. ${ }^{22}$ não encontraram efeito sinérgico $(p=0,12)$ entre a ação das vitaminas C (500mg/dia) e E (400 IU de $\alpha$-tocoferol/dia) suplementadas durante dois meses, nos níveis urinários de PGF2-alfa-8-isoprostano, marcador da peroxidação lipídica.

A avaliação do potencial antioxidante in vivo dos compostos não-enzimáticos depende de algumas variáveis, entre elas: absorção e biodisponibilidade em condições fisiológicas; concentração plasmática ideal para desempenhar sua atividade antioxidante; tipos de radicais livres gerados no processo oxidativo; em qual compartimento celular foram gerados e como foram gerados ${ }^{3}$.

A ação de determinado antioxidante pode, portanto, variar de acordo com o compartimento celular ou tecido no qual atua. A vitamina $C$ apresenta intensa atividade antioxidante contra radicais livres gerados em meio hidrofílico. No entanto, tal vitamina pode não ser capaz de inibir os 
radicais livres que propagam as reações de peroxidação lipídica em meios lipofílicos. Já os flavonóides são capazes de agir como antioxidantes, inativando radicais livres em ambos os compartimentos celulares, hidrofílico e lipofílico ${ }^{3}$. Moreira \& Mancini Filho ${ }^{30}$ sugerem que a atividade antioxidante de compostos fenólicos presentes em especiarias (canela, erva doce e mostarda) difere entre sistemas aquoso e lipídico.

Segundo Huang et al., ${ }^{22}$ a vitamina C $(p=0,01)$ mostrou-se capaz de aumentar a capacidade antioxidante total do soro (serum oxygenradical absorbance capacity - ORAC), o que não ocorreu com a vitamina $\mathrm{E}(p=0,52)$. Os autores ressaltam que esse resultado reflete o fato de a vitamina $C$, ao contrário da $E$, desempenhar meIhor atividade antioxidante em meios hidrofílicos.

\section{Marcadores do estresse oxidativo}

Quando a produção de radicais livres e/ou espécies reativas supera a capacidade de ação dos antioxidantes, se favorece a oxidação de biomoléculas, gerando metabólitos específicos, os marcadores do estresse oxidativo, que podem ser identificados e quantificados. Tais marcadores são derivados, sobretudo, da oxidação de lipídeos, proteínas e Ácido Desoxirribonucléico (DNA), sendo os primeiros os de maior expressão $0^{4,13,31}$. Outra forma de abordar a avaliação do estresse oxidativo é a que emprega métodos indiretos, baseados na capacidade antioxidante ${ }^{32}$ (Tabela 2).

Cada vez há maior evidência científica de que o estresse oxidativo desencadeia relevantes implicações sobre os mecanismos que culminam

Tabela 2. Alguns dos marcadores do estresse oxidativo: descrição e fundamento.

\begin{tabular}{|c|c|c|}
\hline Marcadores & Descrição/Fundamento & Referências \\
\hline \multicolumn{3}{|c|}{ Derivados da oxidação de lipídeos } \\
\hline TBARS & Quantificação da formação de MDA & Vincent et al. ${ }^{13}$ \\
\hline Etano e Pentano & $\begin{array}{l}\text { Hidrocarbonetos voláteis, produtos da oxidação dos ácidos graxos } \\
\text { n-3 e n-6 }\end{array}$ & Mayne $^{31}$ \\
\hline LDL-OX & Dano oxidativo à molécula transportadora de colesterol & Mayne $^{31}$ \\
\hline \multicolumn{3}{|c|}{ Derivados da oxidação de proteínas } \\
\hline \multicolumn{3}{|c|}{ Derivados da oxidação de DNA } \\
\hline $8-\mathrm{OHdG}$ & Resultado da oxidação do ácido nucleico, guanina & $\begin{array}{l}\text { Halliwell \& Whiteman'; } \\
\text { Vincent et al. }{ }^{13} ; \text { Mayne }^{31}\end{array}$ \\
\hline 5-HMdU & Resultado da oxidação do ácido nucleico, timina & Mayne ${ }^{31}$ \\
\hline \multicolumn{3}{|c|}{ Capacidade antioxidante } \\
\hline TAS & Antioxidantes totais presentes na amostra & Vincent et al. ${ }^{13}$ \\
\hline FRAP & Antioxidantes que não contêm ligações S-H & Vincent et al. ${ }^{13}$ \\
\hline
\end{tabular}

5-HMdU: 5-Hidroxymetil-2'-Desoxyuridine; 8-epiPGF 20 : Prostaglandin F2-Alfa-8 Isoprostane; 8-OHdG: 8-Hidroxyl-2'-Deoxyguanosine; AA ácido araquidônico (C20:4); DNA: ácido desoxirribonucléico; DHA: ácido docosahexanóico (C22:6); EPA: ácido eicosapentanóico (C20:5); ERON's: espécies reativas de óxido de nitrogêno; FRAP: ferritin-reducing antioxidant power; LDL-ox: lipoproteína de baixa densidade oxidada; MDA: malondialdeído; n-3: ácidos graxos da série ômega 3; n-6: ácidos graxos da série ômega 6; ORAC: oxygen-radical absorbance capacity; S-H: pontes de hidrogênio; TAS: total antioxidant status; TBARS: thiobarbituric reactive acid susbstances.

Fonte: Adaptado de Barbosa et al. ${ }^{16}$. 
com o desenvolvimento da sindrome metabólica ${ }^{33}$. Dentre os vários fatores que modulam o estresse oxidativo, destaca-se a dieta ${ }^{31}$. Assim, os marcadores do estresse oxidativo constituem ferramentas notáveis na avaliação dos possíveis efeitos e implicações da dieta sobre o referido processo.

\section{FATORESEXÓGENOS MODULADORES DO ESTRESSE OXI DATIVO}

\section{Dieta}

Paniz et al..$^{25}$ demonstraram que os níveis plasmáticos de vitamina $C$ correlacionaram-se positivamente com os de albumina $(r=0,317$; $p=0,009)$ e com a ALA-D ( $\delta$-aminolevulinate dehydratase activity) $(r=0,308 ; p=0,011)$. Conforme supõem esses autores, a vitamina $C$ tem ação protetora sobre os grupos tiol (-SH) dessas proteínas, uma vez que esses são suscetíveis de oxidação. Observou-se, ainda, correlação negativa $(r=-0,241 ; p=0,042)$ entre a ALA-D e os grupos carbonila. Esses últimos, segundo Halliwell \& Whiteman ${ }^{4}$, consistem nos marcadores de maior relevância da oxidação de proteínas.

A suplementação de vitamina C (1,5g/dia) em indivíduos diabéticos, por três meses, não foi capaz de reduzir os níveis plasmáticos de PGF2-alfa-8-isoprostano (Média-M=95, Desvio-Padrão-DP $=4$ versus $M=99, D P=5 \mathrm{pg} / \mathrm{mL}$; $p>0,05)$, apesar do aumento significativo nos níveis plasmáticos da referida vitamina $(M=58$, $\mathrm{DP}=6$ versus $\mathrm{M}=122, \mathrm{DP}=10 \mu \mathrm{mol} / \mathrm{L} ; p<0,01)^{21}$. $\mathrm{O}$ PGF2-alfa-8-isoprostano é o composto mais abundante entre os F2-isoprostanos, marcadores da peroxidação lipídica, derivados da ação de radicais livres sobre os ácidos graxos poli-insaturados, especialmente o ácido araquidônico ${ }^{34}$.

Em estudo com cultura de células, foram administradas as vitaminas C (60mM) e E ( $2 \mathrm{mM})$ a eritrócitos de ratos previamente incubados com $\mathrm{H}_{2} \mathrm{O}_{2}$. Os resultados mostraram que ambas as vitaminas diminuíram efetivamente $(p<0,05)$ a concentração plasmática de malondialdeído, também marcador da peroxidação lipídica ${ }^{26}$.

Huang et al. ${ }^{22}$ avaliaram, em adultos não fumantes, o efeito isolado das vitaminas $C$ (500mg/dia) e E (400 IU de $\alpha$-tocoferol/dia), suplementadas durante dois meses, bem como o efeito da interação entre elas. Não foi observado efeito sinérgico entre a ação das vitaminas $\mathrm{C}$ e $\mathrm{E}$ em nenhum dos marcadores avaliados: malondialdeído ( $p=0,46)$, F2-isoprostanos $(p=0,23)$ e capacidade antioxidante total do soro (ORAC) $(p=0,13)$. Em relação ao efeito isolado, a vitamina $C$ e não a $E$ se mostrou capaz de agir em pelo menos um dos marcadores em questão, aumentando a ORAC ( $M=194, \mathrm{DP}=75 \mu \mathrm{mol}$ Trolox/L; $p=0,01$ ).

Meagher et al..$^{20}$ avaliaram, em adultos saudáveis, o efeito da suplementação de vitamina E durante oito semanas, em diferentes dosagens: 200, 400, 800, 1.200 e 2.000 IU/dia. Nenhuma das dosagens relacionadas foi capaz de exercer efeito sobre os níveis urinários de F2-isoprostanos.

Roberts et al. ${ }^{27}$ observaram que, em indivíduos hipercolesterolêmicos (colesterol total $>200 \mathrm{mg} / \mathrm{dL}$ ), a vitamina E (3.200 IU/dia) reduziu os níveis plasmáticos de F2-isoprostanos após 16 semanas de suplementação $(p<0,005)$. Diante desse resultado, os autores testaram diferentes doses de vitamina $E(0,100,200,400,800,1.600$ e $3.200 \mathrm{IU} / \mathrm{dia})$, durante 16 semanas de suplementação, e verificaram uma tendência linear entre o aumento das doses e a redução percentual nos níveis de F2-isoprostanos. Tal tendência alcançou significância estatística a partir da dose de $1.600 \mathrm{IU} / \mathrm{dia}$ (35 $\pm 2 \% ; p<0,03)$, seguida da de $3.200 \mathrm{IU} / \mathrm{dia}(\mathrm{M}=49, \mathrm{DP}=10 \% ; p<0,005)$.

Ainda em relação à vitamina $\mathrm{E}$, Devaraj et al. ${ }^{24}$ testaram a suplementação de $1.200 \mathrm{IU} / \mathrm{dia}$, durante dois anos, em indivíduos com doença arterial coronariana. Seus níveis plasmáticos correlacionaram-se negativamente com os níveis urinários de F2-isoprostanos $(r=-0,57 ; p<0,0001)$ e liberação de radicais superóxido pelos monócitos $(r=-0,57 ; p<0,0001)$. 
Prasad et al. ${ }^{18}$ referem-se ao zinco como um agente antioxidante altamente eficiente. Estes autores testaram, em indivíduos entre 55 e 87 anos de idade, o efeito antioxidante da suplementação de zinco (45mg de zinco elementar). Após seis meses de suplementação, o zinco mostrou-se capaz de diminuir os níveis plasmáticos de malondialdeído $(M=1,66, D P=0,34$ versus $M=1,35, D P=0,18 ; p=0,002)$ e 8-hidroxil-2'-deoxiguanosina ( $8 \mathrm{HdG})(\mathrm{M}=0,63, \mathrm{DP}=0,16$ versus $M=0,50, D P=0,14 ; p=0,030$ ). O composto 8-OHdG tem sido apontado como o marcador de maior relevância na avaliação do dano oxidativo ao DNA $^{4,31,35}$.

Bruno et al. ${ }^{23}$ testaram, em ratos Sprague Dawley, o efeito de dietas adequadas (AZ; $50 \mathrm{mg}$ de $Z n / k g$ de dieta; $n=12$ ) e deficientes em zinco ( $D Z$; $<0,05 \mathrm{mg}$ de $Z \mathrm{n} / \mathrm{kg}$ de dieta; $\mathrm{n}=12$ ), administradas por 21 dias. O grupo DZ mostrou menores níveis plasmáticos de $\mathrm{F} 2$-isoprostanos $(p<0,05)$ e menor Ferritin-reducing Ability of Plasma (FRAP) $(p=0,039)$. Além do efeito sobre esses marcadores, associaram-se à DZ menores níveis plasmáticos dos antioxidantes: vitamina $C(p=0,003)$ e $\alpha$-tocoferol $(p<0,001)$. O FRAP diz respeito a uma medida da capacidade antioxidante do plasma, pois menor FRAP indica menor capacidade de ligação da ferritina ao ferro e, consequentemente, maior quantidade de ferro livre, capaz de catalisar a geração de radicais $\mathrm{OH}^{\bullet}$, por meio das reações de Fenton e Haber-Weiss ${ }^{7,9}$.

Oteiza et al. ${ }^{19}$ também testaram em ratos Sprague Dawley o efeito de dieta deficiente em zinco ( $D Z ; 0,5 \mu \mathrm{gZn} / \mathrm{g}$ de dieta; $\mathrm{n}=10$ ) sobre marcadores do estresse oxidativo. Após 14 dias, o grupo DZ, quando comparado ao que recebeu dieta adequada em zinco (AZ; $25 \mu \mathrm{gZn} / \mathrm{g}$ de dieta; $n=10$ ), mostrou maiores níveis plasmáticos de grupos carbonila ( $M=3,6, D P=0,2$ versus $M=2,4$, $\mathrm{DP}=0,2 ; p<0,05)$ e TBARS (Thiobarbituric AcidReative Substances) $(\mathrm{M}=39, \mathrm{DP}=3$ versus $M=25$, $\mathrm{DP}=2 ; p<0,05)$. No entanto, não houve efeito significativo sobre o marcador da oxidação ao DNA, o composto 8-hidroxil-2'-deoxiguanosina $(\mathrm{M}=8,9, \mathrm{DP}=1$ versus $\mathrm{M}=6,8, \mathrm{DP}=1 ; p>0,05) . \mathrm{O}$
TBARS, teste das substâncias que reagem com o ácido tiobarbitúrico, dosa os aldeídos, substâncias que se destacam como metabólitos secundários da oxidação de lipídeos. Dentre esses, o malondialdeído é um dos mais abundantes 4,31,36.

Karlsen et al. ${ }^{28}$ avaliaram o efeito da ingestão diária de uma taça de vinho tinto sobre marcadores do estresse oxidativo. Sugere-se que a ação protetora do vinho sobre o estresse oxidativo se dá, especialmente, pela presença dos compostos fenólicos. O estudo foi realizado com 94 indivíduos (31 homens e 57 mulheres) com idade entre 37 e 70 anos. Estes foram divididos em dois grupos: teste ( $150 \mathrm{~mL} /$ dia de vinho tinto) e controle. Independente do sexo, o vinho tinto não foi capaz de exercer efeito sobre nenhum dos marcadores avaliados: FRAP e níveis plasmáticos dos antioxidantes, $\alpha$-tocoferol, $\beta$-caroteno, glutationa e compostos fenólicos totais. Cabe ressaltar que tal estudo teve os seguintes critérios de exclusão: presença de doenças crônicas não transmissíveis, tabagismo, uso de medicamentos (estatinas e aspirinas) e consumo de álcool além do presente no vinho. Estes foram estabelecidos com o objetivo de promover maior homogeneidade da amostra e minimizar os efeitos de possíveis vieses. Destaca-se, aqui, a ampla faixa etária da população estudada e a ausência de controle dos hábitos dietéticos e de atividade física.

Outros fatores dietéticos que não a suplementação de antioxidantes também se mostraram capazes de exercer efeitos sobre o estresse oxidativo. Dentre esses, o de maior expressão é a adequação da ingestão energética ${ }^{37,38}$.

Burneiko et al.$^{37}$ destacam que a ingestão de dietas hiperenergéticas se associa com o desenvolvimento de câncer, doenças degenerativas relacionadas ao envelhecimento, dislipidemia, aterosclerose e doenças cardiovasculares. Os autores ressaltam que o estresse oxidativo vem sendo considerado importante elo em tais associações e que os efeitos benéficos da restrição energética podem estar associados à redução do peso corporal. 
Avaliou-se em ratos Wistar o efeito de Dieta Hiperenergética $(\mathrm{DH})$ sobre marcadores do estresse oxidativo. Após oito semanas de experimentação, comparam-se os grupos DH e controle, não havendo diferenças em relação aos marcadores avaliados: níveis plasmáticos totais de compostos antioxidantes e atividades das enzimas catalase e glutationa peroxidase. Nesse mesmo estudo, os autores encontraram que a interação entre DH e atividade física (natação 2 e 3 vezes/ semana) tiveram efeito pró-oxidante, diminuindo a atividade enzimática da catalase mediante análise do fígado dos animais ${ }^{37}$.

Johnson et al. ${ }^{38}$ investigaram o efeito da ingestão de dieta com restrição energética sobre marcadores do estresse oxidativo. Participaram do estudo dez indivíduos obesos (IMC $>30 \mathrm{~kg} / \mathrm{m}^{2}$ ), os quais receberam, em dias alternados, Dieta Restritiva (DR) com 20\% de redução da ingestão energética normal e Dieta Normal (DN), irrestrita. O grupo DR, comparado ao DN, mostrou menores níveis plasmáticos de grupos carbonila e F2-isoprostanos, após 2, 4 e 8 semanas de intervenção.

\section{Atividade física}

Durante uma atividade física intensa, o consumo total de oxigênio é aumentado em, aproximadamente, dez a vinte vezes. A captação do oxigênio pelo tecido muscular também sofre aumento relevante, da ordem de cem a duzentas vezes. Tais alterações no metabolismo de oxigênio favorecem a geração de radicais livres e/ou espécies reativas não-radicais. A atividade física intensa é capaz de gerar as espécies em questão, por meio da ativação de, pelo menos, três mecanismos principais: produção mitocondrial, citoplasmática e favorecida pelos íons ferro e cobre ${ }^{7}$.

A atividade física intensa, em razão do incremento do consumo de oxigênio, é um fator que predispõe à geração de agentes oxidantes. No entanto, é também hábil em promover mecanismos de adaptação capazes de mitigar os danos oxidativos causados pela ação de tais agentes. Esses mecanismos estão relacionados ao sistema de defesa enzimático e não-enzimático ${ }^{8}$.

Em decorrência da resposta adaptativa mediada pela atividade física, as espécies reativas geradas têm ação de sinalizadores celulares capazes de ativar vias de regulação de genes relacionados à expressão de enzimas e proteínas específicas responsáveis por manter o equilíbrio intracelular entre oxidantes e antioxidantes. A enzima xantina oxidase está envolvida na produção do radical superóxido $\left(\mathrm{O}_{2}{ }^{\circ}\right)$. No entanto, a geração de proteínas com atividade quinase ${ }^{36}$, entre outras ações, é responsável pelo aumento da expressão da superóxido dismutase, defesa antioxidante contra o radical $\mathrm{O}_{2}{ }^{\circ}$.

Souza et al..$^{36}$ ao testar o efeito da atividade física intensa sobre marcadores do estresse oxidativo, observaram que, comparado ao repouso, a corrida em esteira rolante determinou aumento nos níveis plasmáticos de malondialdeído, principalmente decorridos 23 ( $\mathrm{M}=0,21 \mathrm{~m} \mathrm{DP}=0,012$ versus $\mathrm{M}=1,5, \mathrm{DP}=0,009$; aumento de $714 \%$; $p<0,01)$ e 26 minutos $(M=0,21, D P=0,012$ versus $M=1,6, D P=0,013$; aumento de $761 \% ; p<0,01$ ). Os autores ainda ressaltaram que os níveis de malondialdeído relacionaram-se negativamente com a capacidade total do plasma, sendo que esta sofreu redução de $52 \%(M=483, D P=88$ versus $\mathrm{M}=233, \mathrm{DP}=12) ; p<0,01)$ e $59 \%(\mathrm{M}=483$, $D P=88$ versus $M=200, D P=14 ; p<0,01)$, aos 23 e 26 minutos, respectivamente.

Clarkson \& Thompson ${ }^{11}$ ressaltam que a atividade física intensa exerce efeitos sobre os aumentos dos níveis plasmáticos de malondialdeído e concentração de pentano exalado no ar expirado. Esse último marcador, segundo Knutson et al. ${ }^{39}$, decorre da quantificação de compostos voláteis que constitui em outra técnica de aferição da oxidação lipídica. Entre tais compostos destacam-se, principalmente, os hidrocarbonetos etano e pentano, formados mediante peroxidação lipídica dos ácidos graxos poli-insaturados da série ômega 3 e 6, respectivamente.

Burneiko et al. ${ }^{37}$ estudaram, em ratos Wistar, o efeito da atividade física sobre o estresse 
oxidativo. Os ratos foram distribuídos em três grupos $(n=8)$ : sedendário $(S)$, praticantes de atividade física por dois dias/semana (AT2) e cinco dias/semana (AT5). A atividade física eleita foi a natação. Após oito semanas de experimentação, independentemente da frequência de realização da atividade física, o grupo dos ratos ativos mostrou maiores níveis séricos totais de substâncias antioxidantes: AT2 versus $S(M=24,5, D P=2,8$ versus $M=18,9, D P=1,4 ; p<0,05)$ e AT5 versus $S$ $(\mathrm{M}=30,4, \mathrm{DP}=4,4$ versus $\mathrm{M}=18,9, \mathrm{DP}=1,4$; $p<0,05$ ). Tais resultados (aumento dos níveis séricos totais de substâncias antioxidantes) sugerem a ocorrência da resposta adaptativa mediante a realização de atividade física.

Clarkson \& Thompson ${ }^{11}$ ainda destacam que, mediante a realização de atividade física intensa, a suplementação de antioxidantes, especialmente as vitaminas $\mathrm{C}$ e $\mathrm{E}$, é capaz de exercer efeitos sobre a redução de marcadores do estresse oxidativo. No entanto, esses autores discutem a necessidade de tais suplementos diante da existência de resposta adaptativa mediada pela atividade física, hábil em promover mecanismos de proteção contra a geração excessiva de espécies reativas capazes de causar danos às células e aos tecidos.

\section{Tabagismo, álcool e outros fatores}

Segundo Park et al. ${ }^{40}$, o fumo é capaz de alterar os marcadores da peroxidação lipídica, oxidar os grupos tiois das proteínas e aumentar os níveis plasmáticos dos grupos carbonila. Sua ação sobre a oxidação do DNA promove o aumento da geração dos compostos 8-hidroxil-2'-deoxiguanosina. Ressaltam ainda que os níveis plasmáticos de vitamina C e E encontram-se reduzidos em indivíduos fumantes.

A fumaça do cigarro contém mais de 4 mil compostos, incluindo espécies reativas de oxigênio e nitrogênio, com ação potencialmente deletéria sobre as macromoléculas, especialmente sobre os lipídeos ${ }^{41}$. Hu et al. ${ }^{42}$, por meio de método ultra-sensível de quimiluminescência seletiva, confirmaram a presença de níveis consideráveis de peróxido de hidrogênio na fumaça do cigarro. Esta ainda, por ser rica em ferro, pode catalisar a oxidação da Lipoproteína de Baixa Densidade $(\mathrm{LDL})^{43}$. A presença da LDL oxidada (LDLox), agente pró-aterogênico, é evidenciada desde a primeira fase da lesão aterogênica (formação das estrias gordurosas) até a ruptura das lesões na parede vascular, por meio da produção de citocinas específicas que sinalizam a expressão de proteínas quimiotáticas, fatores de crescimento e moléculas de adesão, fatores que implementam o processo inflamatório crônico, característico da aterosclerose ${ }^{44}$.

Park et al. ${ }^{40}$, testaram, em ratos Sprague Dawley, o efeito do fumo sobre marcadores do estresse oxidativo. Os ratos foram submetidos à inalação de fumaça de cigarro, durante um mês, com a frequência de três vezes ao dia. A análise de tecidos de pulmão de ratos do grupo-teste, quando comprado ao controle, mostrou maiores níveis de glutationa oxidada (GSSG; $M=0,74$, $D P=0,06$ versus $M=0,09, D P=0,05 ; p<0,001)$, contrastando com menores níveis de glutationa reduzida ( $G S H ; M=7,92, D P=0,83$ versus $M=14,40$, $\mathrm{DP}=0,58 ; p<0,001)$. O composto 8-hidroxil-2'deoxiguanosina esteve presente em maiores quantidades nos tecidos de pulmonares $(p<0,05)$, hepáticos $(p<0,005)$ e cardíacos $(p<0,05)$ de ratos do grupo teste.

Lykkesleldt ${ }^{41}$, em estudo de revisão, apontou que os níveis dos marcadores de peroxidação lipídica, Thiobarbituric Acid-Reative Substances (TBARS) e malondialdeído, correlacionaram-se positivamente com o hábito de fumar. Entre os 45 estudos revisados, 33 revelaram resultados com significância estatística, a pelo menos, $5 \%$ de probabilidade. Tais resultados referem-se aos maiores níveis dos marcadores em questão, no grupo de indivíduos fumantes quando comparado aos não-fumantes. Os referidos estudos foram todos realizados em humanos. No entanto, variaram quanto ao número de indivíduos participantes, tempo de acompanhamento, número de cigarros, métodos de aferição dos marcadores e fluido 
biológico no qual estes foram medidos (plasma, soro, saliva ou urina).

Os efeitos do álcool sobre o estresse oxidativo podem ser diretos ou ainda mediados por seus metabólitos secundários, sendo marcante sua atuação sobre a redução dos níveis plasmáticos ou séricos dos antioxidantes dietéticos, entre eles: $\alpha$-tocoferol, ácido ascórbico e selênio ${ }^{45}$. Das \& Vasudevan ${ }^{46}$, sugeriram que o metabolismo do etanol está diretamente envolvido na geração de espécies reativas de oxigênio e nitrogênio, bem como na depleção dos componentes do sistema antioxidante e aumento nos níveis de marcadores específicos, sobretudo malondialdeído.

Lecomte et al. ${ }^{47}$, demonstraram que, independente do estado nutricional, o álcool exerce efeito sobre os níveis plasmáticos de vitaminas e minerais antioxidantes, bem como sobre marcadores específicos. Foram estudados 417 homens, entre 29 e 49 anos de idade, consumidores leves ( $<33 \mathrm{~g} / \mathrm{dia} ; \mathrm{M}=1, \mathrm{DP}=10,6$ - 9,2g/dia) e moderados (>33g/dia; M=1, DP=59,0 - 25,7g/dia) de álcool. Comparados a 102 pacientes alcoólatras sem complicações hepáticas, as concentrações plasmáticas de $\alpha$-tocoferol, ácido ascórbico e selênio foram maiores $(p \leq 0,001)$ nos bebedores leves, ao passo que as de malondialdeído foram menores $(p \leq 0,001)$.

Huang et al. ${ }^{48}$ ratificaram o efeito do álcool sobre o estresse oxidativo, analisando em 76 indivíduos alcoólatras, marcadores específicos. Tal análise, quando comparada a do grupo controle (19 indivíduos saudáveis, não bebedores), mostrou níveis séricos significativamente maiores de malondialdeído, enquanto que menor atividade da SOD.

Entre os fatores exógenos, potencialmente geradores de radicais livres, destacam-se ainda os xenobióticos, radiações ionizantes, metais pesados, entre outros ${ }^{41}$.

Os xenobióticos promovem, via citocromo P-450 ou ciclo redox, a produção de espécies reativas de oxigênio. Um mediador de baixo peso molecular do ciclo redox, usualmente flavina ade- nina dinucleotídeo, age como aceptor de elétrons do xenobiótico em questão e sequencialmente, transfere este elétron a outro aceptor, desta vez o oxigênio, gerando assim radicais superóxido. $\mathrm{Na}$ presença de antimicina A (antibiótico produzido por bactérias do gênero Streptomyces), alguns intermediários da cadeia transportadora de elétrons, como a ubiquinona, se auto-oxidam dando lugar à perda de elétrons e consequente formação de radicais superóxido ${ }^{49}$. Os anti-inflamatórios não-esteróides (AINEs) induzem a geração de radicais superóxido, via ativação da NADPH oxidase, complexo enzimático transmembrana gerador do radical superóxido. Li et al. ${ }^{50}$, demonstraram que mediante a administração AINE houve aumento na expressão de NADPH oxidase e P22phox (subunidade necessária a ativação enzimática) em tecido cardíaco e aorta de ratos hipertensivos. Os autores ainda evidenciaram tais resultados em células endoteliais humanas.

As radiações ionizantes promovem a instauração do estresse oxidativo, entre os mecanismos propostos destacam-se: a ativação das NADPH oxidases, a disfunção da cadeia transportadora de elétrons mitocondrial e a redução da atividade das enzimas antioxidantes, sobretudo da SOD-Mn. Lemon et al. ${ }^{51}$ demonstraram maiores níveis de 8-Hidroxyl-2'-Deoxyguanosine (8-OHdG), marcador de dano oxidativo ao DNA (ácido nucléico guanina), em ratos submetidos à radiação gama (yH2AX) proveniente de uma fonte radiotiva de césio $\left({ }^{137} \mathrm{Cs}\right)$. Outros estudos ratificam o efeito das radiações ionizantes sobre marcadores do estresse oxidativo, sobretudo os referentes ao dano oxidativo ao DNA ${ }^{52-54}$, decorrentes dos processos mutagênicos, aberrações cromossômicas, instabilidade genômica e alterações teloméricas ${ }^{51}$.

O acúmulo de metais pesados em um sistema biológico propicia a catálise de reações que culminam na geração de espécies reativas de oxigênio, e ainda pode exercer influência sobre os mecanismos de defesa antioxidante, sobretudo o enzimático ${ }^{43,55}$. Farombi et al..$^{55}$, por meio de espectrofotometria de absorção atômica, eviden- 
ciaram a presença de altos níveis de metais pesados (arsênio, chumbo, cádmio, cobre e zinco) nas águas do rio Ogun (Nigéria, África). Posteriormente, demonstraram que nos peixes nativos deste rio houve diminuição da atividade das enzimas superóxido dismutase e catalase, alterações no ciclo redox da glutationa e, ainda, indução da peroxidação lipídica.

\section{CONSIDERA ÇÕES FINAIS}

A instalação do estresse oxidativo se dá por meio de um desequilíbrio entre os fatores pró-oxidantes e antioxidantes, em favor dos primeiros. O sistema de defesa antioxidante tem o objetivo primordial de manter o processo oxidativo dentro dos limites fisiológicos e passíveis de regulação, impedindo que os danos oxidativos se amplifiquem, culminados em danos sistêmicos irreparáveis. Os mecanismos de geração de radicais livres ocorrem, sobretudo, nas mitocôndrias, membranas celulares e no citoplasma.

A dieta é, sem dúvida, um fator de grande importância na modulação do estresse oxidativo. Os efeitos da suplementação de vitaminas e minerais antioxidantes sobre o estresse oxidativo não são ainda conclusivos, sobretudo em relação à dose e ao tempo de suplementação. No entanto, os estudos de suplementação têm conseguido demonstrar efeitos positivos sobre biomarcadores específicos, sendo os relacionados à oxidação de lipídeos (malondialdeído e isoprostanos) os de maior relevância. Tais divergem em relação às condições dos indivíduos (sexo, idade, índice de massa corporal, estado de saúde, uso de fármacos, hábitos de vida, entre outros) e também existe a variabilidade relacionada à intervenção (dose e tempo de suplementação, conteúdo dos componentes antioxidantes e administração de um componente isolado ou em combinação com outros). Tais fatores dificultam a interpretação dos resultados destes estudos, bem como podem ser determinantes dos resultados ainda não conclusivos.
O efeito da dieta hiperenergética sobre a instauração do estresse oxidativo, possivelmente, é mediado pela redução do peso corporal. Existem evidências de que os fatores exógenos tais como: xenobióticos, radiações ionizantes, metais pesados, tabagismo e ingestão de álcool agem sobre a geração de radicais livres, bem como sobre a atuação dos sistemas de defesa antioxidante, no entanto, ainda não é possível determinar com segurança, sobretudo em humanos, os níveis de exposição que seriam potencialmente nocivos.

\section{OLABORADORES}

K.B.F. BARBOSA, J. BRESSAN, N.M.B. COSTA, R.C.G. ALFENAS, S.O. PAULA e V.P.R MINIM participaram da concepção, do desenho do estudo, da análise, da interpretação dos dados e da redação final do artigo.

\section{REFERÊ NCIAS}

1. Shami NJIE, Moreira EAM. Licopeno como agente antioxidante. Rev Nutr. 2004; 17(2):227-36. doi: 10.1590/S1415-52732004000200009.

2. Ferreira ALA, Matsubara LS. Radicais livres: conceitos, doenças relacionadas, sistema de defesa e estresse oxidativo. RAMB. 1997; 43(1):61-8.

3. Bianchi MLP, Antunes LMG. Radicais livres e os principais antioxidantes da dieta. Rev Nutr. 1999; 12(12):123-30. doi: 10.1590/S1415-52731999000 200001.

4. Halliwell B, Whiteman M. Measuring reactive species and oxidative damage in vivo and in cell culture: how should you do it and what do the results mean? Br J Pharmacol. 2004; 142(2): 231-55.

5. Green K, Brand MD, Murphy MP. Prevention of mitochondrial oxidative damage as a therapeutic strategy in diabetes. Diabetes. 2004; 53(Suppl 1): 110-8.

6. Ferrari CKB. Functional foods, herbs and nutraceuticals: towards biochemical mechanisms of healthy aging. Biogerontology. 2004; 5(5): 275-9.

7. Koury JC, Donangelo CM. Zinco, estresse oxidativo e atividade física. Rev Nutr. 2003; 16(4):433-41. doi: 10.1590/S1415-52732003000400007.

8. Schneider CD, Oliveira AR. Radicais livres de oxigênio e exercício: mecanismos de formação e 
adaptação ao treinamento físico. RBME. 2004; 10(10):308-13.

9. Welch KD, Davis TZ, Eden MEV, Aust SD. Deleterious iron-mediated oxidation of biomolecules. Free Radic Biol Med. 2002; 32(7): 577-83.

10. Bernard K, Krause KH. The NOX family of ROSgenerating NADPH oxidases: physiology and pathophysiology. Physiol Rev. 2007; 87(1):245-313.

11. Clarkson PM, Thompson HS. Antioxidants: what role do they play in physical activity and health? Am J Clin Nutr. 2000; 72(2):637-46.

12. Rodrigo R, Guichard C, Charles R. Clinical pharmacology and therapeutic use of antioxidant vitamins. Fundam Clin Pharmacol. 2007; 21(2): 111-27.

13. Vincent HK, Innes KE, Vincent KR. Oxidative stress and potential interventions to reduce oxidative stress in overweight and obesity. Diabetes Obes Metab. 2007; 9(6):813-39.

14. Visioli F, Riso P, Grande S, Galli C, Porrini M, Protective activity of tomato products on in vivo markers of lipid oxidation. Eur J Nutr. 2003; 42(4): 201-6.

15. Fito $M$, de la Torre $R$, Farre-Albaladejo $M$, Khymenetz O, Marrugat J, Covas MI. Bioavailability and antioxidant effects of olive oil phenolic compounds in humans: a review. Ann Inst Super Sanita. 2007; 43(4):375-81.

16. Barbosa KBF, Bressan J, Zulet MA, Martínez JA. Influencia de la dieta sobre marcadores plasmáticos de estrés oxidativo en humanos. An Sist Sanit Navar. 2008; 31(3):259-80.

17. Rover Jr L, Hoehr NF, Vellasco AP. Sistema antioxidante envolvendo o ciclo metabólico da glutationa associado à métodos eletroanalíticos na avaliação do estresse oxidativo. Quím Nova. 2001; 24(1): 112-9.

18. Prasad AS, Beck FWJ, Bao B, Fitzgerald JT, Snell DC, Steinberg JD, et al. Zinc supplementation decreases incidence of infections in the elderly: effect of zinc on generation of cytokines and oxidative stress. Am J Clin Nutr. 2007; 85(3): 837-44.

19. Oteiza PI, Olin KL, Fraga CG, Keen CL. Zinc deficiency causes oxidative damage to proteins, lipids and DNA in rat testes. J Nutr. 1995; 125(4): 823-9.

20. Meagher EA, Barry OP, Lawson JA, Rokach J, FitzGerald GA. Effects of vitamin $E$ on lipid peroxidation in healthy persons. JAMA. 2001; 285(9):1178-82

21. Darko D, Dornhost A, Kelly FJ, Ritter JM, Chowienczyk PJ. Lack of effect of oral vitamin C on blood pressure, oxidative stress and endothelial function in type II diabetes. Clin Sci. 2002: 103(4): 339-44.

22. Huang HY, Appel $\amalg$, Croft KD, Miller ER, Mori TA, Puddey IB. Effects of vitamin $C$ and vitamin $E$ on in vivo lipid peroxidation: results of randomized controlled trial. Am J Clin Nutr. 2002; 76(3): 549-55.

23. Bruno RS, Song Y, Leonard SW, Mustacich DJ, Taylor AW, Traber MG, et al. Dietary zinc restriction in rats alters antioxidant status and increase plasma F2 isoprostanos. J Nutr Biochem. 2007; 18(8): 509-18.

24. Devaraj S, Tnag R, Adams-Huet B, Harris A, Seenivasan T, Lemos JA, et al. Effect of high-dose $\alpha$-tocopherol supplementation on biomarkers of oxidative stress and inflammation and carotid atherosclerosis in patients with coronary artery disease. Am J Clin Nutr. 2007; 86(5):1392-8.

25. Paniz C, Bairros A, Valentini J, Charao M, Bulcao $R$, Moro $A$, et al. The influence of the serum vitamin $C$ levels on oxidative stress biomarkers in elderly women. Clin Biochem. 2007; 40(18):1367-72.

26. Reddy CSSS, Subramanyam MV, Vani R, Devi SA. In vitro models of oxidative stress in rat erythocytes: effect of antioxidant supplements. Toxicol In Vitro. 2007; 21(8):1355-64.

27. Roberts LI, Oates JA, Linton MF, Fazio S, Meador $\mathrm{BP}$, Gross MD, et al. The relationship between dose of vitamin $\mathrm{E}$ and suppression of oxidative stress in humans. Free Radic Biol Med. 2007; 43(10): 1388-93.

28. Karlsen A, Retterstol L, Laake P, Kjolsrud-Bohn, Sanvik L, Blomhoff R. Effects of a daily intake of one glass of red wine on biomarkers of antioxidante status, oxidative stress and inflammation in healthy adults. e-SPEN. 2007; 2(1):127-33.

29. Duarte $T L$, Jones GD. Vitamin C modulation of $\mathrm{H} 2 \mathrm{O} 2$-induced damage and iron homeostasis in human cells. Free Radic Biol Med. 2007; 43(8): 1165-75.

30. Moreira AVB, Mancini Filho J. Atividade antioxidante das especiarias mostarda, canela e erva-doce em sistemas aquoso e lipídico. Nutrire Rev Soc Bras Aliment Nutr. 2003; 25:31-46.

31. Mayne ST. Antioxidant nutrients and chronic disease: use of biomarkers of exposure and oxidative stress status in epidemiologic research. J Nutr. 2003; 133(Suppl 3):933-40.

32. Huang D, Ou B, Prior RL. The chemistry behind antioxidant capacity assays. J Agric Food Chem. 2005; 53(6):1841-56.

33. Furukawa $S$, Fujita $T$, Shimabukuro $M$, Iwaki $M$, Yamada $Y$, Nakajima $Y$, et al. Increased oxidative 
stress in obesity and its impact on metabolic syndrome. J Clin Invest. 2004; 114(12):1752-61.

34. Roberts $L$, Morrow JD. Products of the isoprostane pathway: unique bioactive compounds and markers of lipid peroxidation. Cell Mol Life Sci. 2002; 59(5):808-20.

35. Halliwell B. Why and how should we measure oxidative DNA damage in nutricional studies? How far have we come? Am J Clin Nutr. 2000; 72(5):1082-7.

36. Souza Jr TP, Oliveira PR, Pereira B. Efeitos do exercício físico intenso sobre a quimioluminescência urinária e malondialdeído plasmático. RBME. 2005; 11(1):91-6.

37. Burneiko RCM, Diniz YS, Galhardi CM, Rodrigues $H G$, Ebaid GM, Faine LA, et al. Interaction of hypercaloric diet and physical exercise on lipid profile, oxidative stress and antioxidant defenses. Food Chem Toxicol. 2006; 44(7):1167-72.

38. Johnson JB, Summer W, Cutler RG, Martin B, Hyun $\mathrm{DH}$, Dixit VD, et al. Alternate day calorie restriction improves clinical findings and reduces markers of oxidative stress and inflammation in overweight adults with moderate asthma. Free Radic Biol Med. 2007; 42(5):665-74.

39. Knutson MD, Handelman GJ, Viteri FE. Methods for measuring ethane and pentane in expired air from rats and humans. Free Radic Biol Med. 2000; 28(4):514-9.

40. Park EM, Park YM, Gwak YS. Oxidative damage intissues of rats exposed to cigarette smoke. Free Radic Biol Med. 1998; 25(1):79-86.

41. Lykkesleldt J. Malondialdehyde as biomarker of oxidative damage to lipids caused by smoking. Clin Chim Acta. 2007; 380(1-2):50-8.

42. Hu Y, Zhang Z, Yang $C$. The determination of hydrogen peroxide generated from cigarette smoke with an ultrasensitive and highly selective chemiluminescence method. Anal Chim Acta. 2007; 601(1):95-100.

43. Halliwell B, Gutteridge JMC. Role of free radicals and catalytic metal ions in humans disease: an overview. Methods Enzymol. 1990; 186(1):1-85.

44. Horkko S, Binder CJ, Shan PX, Chang MK, Silverman G, Palinski W, et al. Immunological responses to oxidized LDL. Free Radic Biol Med. 2000; 28(12):1771-9.

45. Ward RJ, Jutla J, Peters TJ. Antioxidants status in alcoholic liver disease. Adv Biosci. 1989; 76(5): 343-51.
46. Das SK, Vasudevan DM. Alcohol-induced oxidative stress. Life Sci. 2007; 81(3):177-87.

47. Lecomte $E$, Herbeth $B$, Pirollet $P$, Chancerelle $Y$, Arnaud J, Musse N, et al. Effect of alcohol consumption on blood antioxidant nutrients and oxidative stress indicators. Am J Clin Nutr. 1994; 60(2):255-61.

48. Huang MC, Chen CC, Peng FC, Tang SH, Chen $\mathrm{CH}$. The correlation between early alcohol withdrawal severity and oxidative stress in patients with alcohol dependence. Prog Neuropsychopharmacol Biol Psychiatry. 2009; 33(1):66-9.

49. Montero M. Los radicales libres y las defensas antioxidantes: revisión. Ann Fac Med. 1996; 57(4):278-81.

50. Li H, Hortmann M, Daiber A, Oelze M, Ostad MA, Schwarz PM, et al. Cyclooxygenase 2-Selective and Nonselective Nonsteroidal Anti-Inflammatory Drugs Induce Oxidative Stress by Up-Regulating Vascular NADPH Oxidases. JPET. 2008; 326(3):745-53.

51. Lemon JA, Rollo CD, Boreham DR. Elevated DNA damage in a mouse model of oxidative stress: impacts of ionizing radiation and a protective dietary supplement. Mutagenesis. 2008; 23(6): 473-82.

52. Saad AH, Zhou Y, Lambe EK. Hahn GM. Mutagenesis in mammalian cells can be modulated by radiation induced voltagedependent potassium channels. Mutat Res. 1994; 324(4):171-6.

53. Spitz DR, Azzam El, Jian LJ, Gius D. Metabolic oxidation/reduction reactions and cellular responses to ionizing radiation: a unifying concept in stress response biology. Cancer Metastasis Rev. 2004; 23(3-4):311-22.

54. Kim GJ, Fiskum GM, Morgan WF. A role for mitochondrial dysfunction in perpetuating radiation-induced genomic instability. Cancer Res. 2006; 66(21):10377-83.

55. Farombi EO, Adelowo OA, Ajimoko YR. Biomarkers of oxidative stress and heavy metal levels as indicators of environmental pollution in African cat fish (Clarias gariepinus) from Nigeria Ogun River. Int J Environ Res Public Health. 2007; 4(2):158-65.

Recebido em: 13/3/2008

Versão final reapresentada em: 3/12/2009 Aprovado em: 17/3/2010 